\title{
ALGUNAS COSTUMBRES GINECOBSTETRICAS EN LA ERA PREHISPANICA
}

\author{
Fernando Sánchez-Torres*
}

Para mala fortuna de los curiosos, poco sabemos de las costumbres de nuestros antepasados los chibchas 0 muiscas, que habitaban la región central de la actual Colombia. Es seguro que si la censura española no hubiera eliminado el extenso tratado que sobre ellos escribió Fray Pedro de Aguado, primer cronista del Nuevo Reino, en su obra "Recopilación Historial", muchos hechos interesantes se podrían relatar en este capítulo. Más todavía, las obras del licenciado Jiménez de Quesada, "Los ratos de Suesca" y el "Compendio Historial", se hallan refundidos no se sabe dónde. Realmente, la mutilación de los escritos de aquel y la pérdida de los de este son, como anota Juan Friede, un suceso lamentable pues esas crónicas fueron emprendidas hacia la mitad del siglo XVI, al tiempo que aún estaba viva la cultura muisca.

Sin embargo, aunque el documento es la base de la historia, no es la historia misma; así lo creía don Baldomero Sanín Cano. Por eso, para el objeto que nos ocupa, si queremos tener noción de las costumbres de los chibchas hemos de apelar a leyendas $y$ tradiciones. $Y$, al fin $y$ al cabo, las tradiciones, en parte equivocadas, contienen - como decía Renan- una porción de verdad que la historia no debe mirar con indiferencia.
... Y cuenta la tradición que llegó una vez un hombre al valle de Ganza, a un sitio que llamaban Toyú. Allí, en una cueva, permaneció algún tiempo predicando y enseñando cosas buenas. Traía en la mano una macana y en la cabeza y brazos hecha la señal de la cruz. Fue llamado con distintos nombres: Sadigua (nuestro pariente y padre), Sugamonxe (santo que se hace invisible), Sugansua (hombre que desaparece); pero es con el de Nemqueteba como mejor se le conoce. El lugar por el cual se marchó para siempre el venerable patriarca denomináronlo Sugamuxi, o sea "el desaparecido". El pueblo chibcha lloró su ausencia y el recuerdo, al decir de Arango Cano, "tornose en mito y éste, repetido, divinizó a Nemqueteba, colocándolo en lugar preferido en su fantástico panteón de dioses".

Tan grande fue su influjo en la vida de los muiscas que las mujeres embarazadas, para que tuvieran un buen parto, iban en peregrinación hasta Iza, pueblo cercano a Sogamoso, y raspaban una piedra que creían que conservaba la huella de su pie; luego bebían ese polvo mezclado con agua. Este rito, afirma Diepgen, recuerda algunos similares practicados

* Profesor Asociado del Departamento de Obstetricia y Ginecología. Facultad de Medicina de la Universidad Nacional. 
por los pueblos germánicos y celtas. En otras ocasiones, y con la misma intención, ofrendaban sus cintillas $y$ figuras de oro al Cuchavira o Cuchaviva, vale decir, al arco iris.

En el momento supremo de la gestación las aborígenes buscaban, solas, las orillas de los ríos o las lagunas para dar a luz allí. Es seguro que adoptaran instintivamente la posición en cuclillas, tal como acostumbraron todas las mujeres en todas las latitudes de la tierra, hasta el instante en que al famoso tocólogo francés Mauriceau se le ocurrió que debía de ser en la cama y en decúbito dorsal.

No había parteras entonces porque, según el Padre Simón, "no son menester; antes, cuando quieren parir, huyen, si pueden, de la gente $y$ se van a esconder cerca de un arroyo para, en pariendo, entrarse en él a lavarse con su parto". El Padre Zamora también sostiene que "jamás tuvieron parteras, ni las usaron hasta que enseñaron este ejercicio las mujeres españolas".

Está claro, pues, que los partos normales eran atendidos por las mismas parturientas. Pero quizás en aquellos casos difíciles, y atraída por los gritos, alguna india vecina las acompañaba en el doloroso y dramático trance. Tampoco es improbable que esta acompañante en ocasiones abandonara su actitud pasiva $y$ procurara ayudar al nacimiento, adelantándose así a las "comadres sabias" que llegaron con los conquistadores.

A pesar de que los muiscas tenían sus médicos-sacerdotes, a los cuales denominaban ogques, y los españoles xeques 0 jeques, no hay constancia de que se apelara a su arte para cuestiones obstétricas. $Y$ seguramen- te no, pues, hecho curioso, desde las épocas primitivas hasta bien entrado el siglo XVII, al hombre le estuvo vedado presenciar el acto del nacimiento y mucho menos intervenir en él.

Pasado el alumbramiento, como hemos visto, lavaban la criatura y se lavaban ellas para retornar al bohío. Aunque la covada, o costumbre de que los maridos asumieran el papel de puérperas y disfrutaran con largueza de todas las prerrogativas de éstas, fuera practicada en muchas partes del mundo, particularmente en la América del Sur, entre los muiscas parece que no tuvo vigencia. Tan solo sabemos por el Padre Simón que era ley inviolable "no acercarse el marido a la mujer hasta muchos días después de haber parido".

En la época del destete el infante, simbólicamente, era depositado sobre unos juncos rociados con leche materna y arrojado a las aguas de la laguna; unos mancebos cuidaban la débil barquilla. Si naufragaba el porvenir iba a ser amargo y duro para el niño; y si no, desde ese instante se celebraba con júbilo la vida larga y venturosa que le esperaba.

Que muriera la mujer durante el parto no debía ser cosa infrecuente. Entre las leyes del cacique Nemequene existía una que obligaba al marido a indemnizar a la familia de su mujer, si ésta fallecía. Este hecho, y otros que mencionaremos adelante, ponía de presente el matriarcado que imperaba entre los chibchas. Es posible que la muerte de las parturientas fuera considerada acontecimiento digno de recompensa, honrando sus despojos, como si fuesen héroes muertos en el campo de batalla, e indemnizando a sus deudos. El cronista Juan de Castellanos relata así la disposición de Nemequene: "Man- 
dó que si de parto pereciese cualquier mujer casada, su marido perdiese la mitad de la hacienda y la diese al suegro y a la suegra, hermanos o parientes más cercanos; en defecto de padres, mas quedando viva la criatura, no debía más que la criase a su costa". Por su parte, el Padre Simón añade que si el marido no tenía hacienda "había de buscar algunas mantas con qué pagar a los herederos la muerte, y si no, le perseguían hasta quitarle la vida". Roberto de Zubiría considera que esta ley de Nemequene estaba encaminada a proteger a la mujer embarazada pues ante semejantes castigos el esposo tendría que prodigar y procurar extremados cuidados a su esposa durante el parto.

Desconocemos ciertamente la idea que tenían los chibchas acerca de la paternidad para que obraran así. ¿Conocían acaso la paternidad fisiológica? Dice Pérez de Barrada que ni se puede afirmar ni negar. Pero el hecho de que en lengua muisca el vocablo b-xi-scua significara cohabitar y parir, presume el reconocimiento de una relación directa entre ambos actos. Además, la sanción impuesta al marido que perdiera su cónyuge en el curso del parto implicaba de por sí cierta participación suya en el proceso que tan mal había culminádo. Fuera de esto, el concepto que tenían del embarazo múltiple refuerza esa presunción. Para los chibchas el que una mujer diera a luz hijos gemelos era un acto monstruoso; por eso mataban al segundo. Para ellos era el fruto de una lujuria desenfrenada pues creían "ser imposible engendrar dos juntamente, sino que había de ser uno después del otro, con distintos ayuntamientos". No hay duda, según esta creencia, que Bachué fue el prototipo de la extrema lujuria. Recordemos cómo imagina- ban la creación del hombre: Hecha la luz apareció una mujer a quien llamaron Bacuche, es decir, "mujer buena", la cual sacó de las aguas a un niño de tres años y marchó con él al pueblo de Yguaque, distante cuatro leguas de la ciudad de Tunja. "Criólo hasta que tuvo edad para casarse con él, y de cada parto nacían cuatro, o seis hijos, de cuya generación se llenó la tierra".

$\mathrm{Si}$ seguimos fieles a las leyendas, la gestación, como en la mitología de otros pueblos, podía ser el producto de la acción de los dioses... Y refieren que en aquel tiempo hubo dos doncellas, hijas del cacique de Guachetá, que deseando concebir de los destelleos del divino Sol permaneciendo vírgenes, todos los días, al despuntar el alba, a hurtadillas salían del cercado de sus padres. En un lugar propicio se recostaban a esperar que fueran tocadas por los primeros ímpetus solares. Muy pronto "la una apareció como preñada, que ella decía del Sol..." ( $P$. Simón). Creemos, según esta leyenda, que para los españoles fue liviana empresa la conquista de las muiscas ya que eran considerados "hijos del Sol".

Otras costumbres dignas de mención eran aquellas relacionadas con la menarca o aparición de la primera menstruación. Bien sabemos que este hecho fisiológico siempre ha tenido algo de tabú. La doncella muisca en quien el flujo sanguíneo denunciaba su madurez sexual, tenía que someterse a una ceremonia purificadora muy particular, parecida a la que acostumbraban los taironas, en la región de Santa Marta. Cubierta con una manta la cabeza debía permanecer sentada seis días en el rincón de un bohío; luego, entre doble hilera de indios, marchaba hasta una laguna en cuyas aguas se lavaba para quedar purificada. Desde este ins- 
tante se le denominaba deipape, que según el $P$. Simón equivalía a "doña Fulana". Retornaba a su casa y se iniciaba allí un jolgorio animado con chicha. José Pérez dice que el nombre que recibía era ipaque y que para Lehmann significaba "señora", o simplemente "mujer"; en otros términos, apta para la vida sexual y el matrimonio.

Volviendo a lo del matriarcado chibcha, era usanza que los caciques fueran azotados por sus mujeres, particularmente al calor de los celos. Pero, cosa paradójica, algunos privilegiados como el sacerdote Sugamuxi o el zaque de Tunja, mantenían en sus casas hasta trescientas tyguyes o concubinas; los demás caciques poseían cuantas pudieran sustentar. Además, si a los caciques llegaba noticia de doncellas hermosas presurosos las solicitaban a sus padres y éstos estaban en la obligación de concedérselas. En cambio a los jeques o médicos sacerdotes se les obligaba a vivir en el celibato porque "teniéndolos por hombres santos, a quienes respetan, honran y veneran, y con quienes se consultan cosas graves, no les parece cosa conveniente que sean lujuriosos y lascivos" (Castellanos).

Para que no quede duda de ese matriarcado que hemos venido mencionando, la esposa principal, que era la que góbernaba la casa, tenía el derecho de exigir a su marido que una vez muerta no tuviera "carnal ayuntamiento" por el término que ella señalara, y que la ley limitaba a cinco años.

Soltera, la mujer muisca disfrutaba de plena libertad sexual, pero su entrega debía de ser voluntaria. Al respecto, era admirable la severidad del código de Nemequene: moría indefectiblemente quien siendo soltero forzase a una india, pero si era ca- sado dos solteros tenían que dormir con su mujer y gozar de ella. Es seguro que esta disposición de Nemequene se viera burlada con frecuencia si nos atenemos a lo que cuenta Rodríguez Freire. Dice el cronista que por allá en 1538 -cronología puesta en duda por Juan Friedelos ejércitos del cacique Guatavita y los del teniente Bogotá, convinieron una tregua de treinta días para cumplir con los dioses antes de librar la batalla. De uno y otro bando hombres y mujeres bailaron al són de sus instrumentos; luego comieron y bebieron juntos "en grandes borracheras que hicieron, que duraban de día y de noche, a donde el que más incestos y fornicaciones cometía era más santo". Con razón, aducimos nosotros, la virginidad era despreciada entre los muiscas. "Reparaban poco -anota el Padre Zamora- en no hallar doncellas a sus mujeres, y en algunos era motivo para aborrecerlas si las hallaban con integridad, porque decían eran mujeres desgraciadas que no hubo quien hiciera caso de ellas".

En cuanto a las costumbres de otras culturas son también muy escasas las noticias que tenemos. Veamos lo poco que de ellas se sabe.

Los naturales que habitaban la provincia de Tocaima devoraban a su primogénito en una fiesta pública y las mujeres se condolían cuando les nacían hembras, ya que todas eran muy inclinadas a la guerra. Esa costumbre de sacrificar a su primer hijo también existía entre los guayupes, que ocupaban la región de los Llanos Orientales. La forma de darles muerte era enterrándolos vivos o echándolos río abajo. Sus prácticas eran todavía más repugnantes pues si el segundo parto era de una criatura hembra y algún indio decía que por ello no valía nada y no merecía 
la pena criarla, la mataban; y lo mismo hacían con la tercera y la cuarta. Inmolaban, pues, a sus hijos sin motivo alguno o, como anota Emilio Robledo, por "daca allá esas pajas".

Los indios justificaban su proceder diciendo que los primeros hijos "son aviesos y traviesos y consumen mucho la juventud de las madres y las envejecen".

Los panches o tapaces, que ocupaban las orillas del río Magdalena desde las hoyas del Gualí y del Rionegro hasta las del Fusagasugá y del Coello, acostumbraban extirpar el clítoris a las recién nacidas, según relata Fray Pedro de Aguado. "Tienen estos bárbaros - dice el cronista- una ceremonia o costumbre muy perjudicial y dañosa para ellos, aunque no hacen mucho caso del daño que de ella se les sigue y viene; y es que a las criaturas hembras que les nacen, a los ocho o diez días, así como nacen, les cortan con unas cañas o piedras cierta parte de carne que en el miembro o vaso mujeril tienen, y lo que les cortan lo secan y hacen polvo con los cuales después le refriegan la herida, para que se consuma y seque la otra parte que queda 0 puede crecer, para que no crezca y quede igual, y así muchas criaturas mueren de estas heridas, y así entre ellos haya muy pocas hembras". Más adelante refiere Aguado que "los casamientos entre esta nación se hacen con mucha facilidad, porque en estando la criatura sana de la herida que dije le dan a los ocho o diez días, luego el indio que la quiere por mujer da a la madre una sarta de cuentas o una pampanilla... y así queda hecho el casamiento; esta sarta o pampanilla ha de guardar la madre para cuando la desposada sea de edad para poderla traer; estos casamientos se deshacen por hacer ella adulterio a su marido y no por otra causa, que en tal caso él la puede dejar".

Parece, por referencia de R. Leonardo, que la circuncisión de las mujeres era una práctica muy antigua, como que los egipcios la llevaban a cabo, al igual que algunas tribus africanas. Por su parte, Robledo dice que este procedimiento quirúrgico puede considerarse como un elemento cultural Karib, poco conocido de los etnólogos. Los chama, del río Ucayali, lo ejecutaban durante la pubertad de las jóvenes, ceremonia que revestía gran solemnidad y que el Marqués de Wavrin relató así: "Para realizarla escogen la estación seca y aunque participan a los de la tribu, tienen precauciones para que no se adviertan los extranjeros. Los preparativos son grandes, especialmente en chicha para las bebezones, legumbres para atender a los invitados, piezas de caza como jabalíes o paujíes engordados con tal fin, etc. La ceremonia empieza con bailes y grandes libaciones. La joven que va a ser circuncidada debe participar en las fiestas aún más que las otras personas, pues hace parte de los ritos el que ella llegue a tal estado de inconsciencia. En dos troncos de madera blanca y ligera de palo de balsa (Ochroma), apareados en forma de mesa, extienden la paciente cuatro mujeres ancianas que han sido escogidas como cirujanas. Los parientes y amigos forman círculo alrededor de la paciente para ponerla a buen recaudo de las miradas de los extraños. Una de las cuatro cirujanas se provee de un cuchillo de bambú bien cortante. De ninguna manera se admite arma de metal. Descubiertas las piernas las ayudantas las sujetan fuertemente a fin de inmovilizar las pacientes mientras la operante corta de un tajo el clítoris. Los chama pretenden con esta operación el que la 
mujer no tenga más excitación genésica que la de la cópula, pero también dicen que con la extirpación de aquel órgano se evitan malos olores".

Curiosa también era entre los guayupes la celebración del nacimiento del segundo hijo. El padre era encerrado en un bohío, pero antes muchos indios lo azotaban con hojas de ortiga; luego cada uno de los doce individuos más ancianos del pueblo le arrancaban un mechón de pelo. Durante una luna, que era un mes, sólo le alimentaban con mazamorra - una taza al día- y cada cinco días un pan o torta de cazabe acompañado de una totuma de vino hecho de cáscara de cedro. Pasado el mes se le sometía nuevamente a ortigamiento y entonces sí se le permitía ver a su mujer y a su hijo.

Los mohanes o noamas eran los médicos hechiceros de los taironas, cuya cultura floreció en la región de Santa Marta y desapareció poco después de la ocupación española; a ellos les estaba señalado un lugar especial para ejercer su oficio, sitio al que los conquistadores denominaron "buhíos del diablo". Allí las doncellas, al iniciar su pubertad, practicaban un ayuno de nueve días, o coime, rito parecido al que hemos visto que usaban los muiscas.

Los cuna, llamados también darién, cuna-cuna o ti ("gentes de los ríos"), que habitaban lo que hoy es el istmo de Panamá, festejaban públicamente la pubertad de las niñas; en ese momento recibían por primera vez un nombre y a partir del año siguiente obtenían el derecho de casarse con el hombre de su agrado. Las mujeres cunas, según Reclus, daban a luz en cabañas aisladas, bajo la vigilancia de una anciana. Aunque ignoramos si tenían participación algu- na, ha de aceptarse que el parto en estas tribus se verificaba ya con acompañamiento. Esa primitiva comadre bañaba luego a la madre y a su hijo en el río y los conducía ante el lelé, que era el cacique o capitán, a la vez sacerdote y médico, para que los fumigara con tabaco y ahuyentara con ello la mala suerte. Si un extranjero llegaba a presenciar el parto de una mujer cuna era sentenciado a muerte.

También entre los cunas como en otras tribus del litoral neogranadino $y$ entre los papiocos o tucanes del bajo Guaviare, la pollazón, o participación solidaria del marido con los dolores del parto, era costumbre arraigada.

Los aruaco, o arhuak, también hacían de la pubertad un rito: el mama - sacerdote designaba a su arbitrio al que debía encargarse de "componer" a la novicia; casi siempre era él mismo quien lo hacía.

Como en la zona central de Colombia, también en algunas provincias del valle del Cauca la virginidad era despreciada, llegando al extremo de que la madre de la novia era quien la desfloraba con sus dedos, antes de entregarla al marido. De la misma manera, en estas provincias el marido se separaba de su mujer encinta, pensando, probablemente, que el acto sexual podía ocasionar daño al feto.

Para los motilones, habitantes de las sierras de Perijá y Bobalí y los valles del Catatumbo y Río de Oro, la sangre menstrual como los órganos sexuales se ocultaban celosamente, pues consideraban que su vista tenía poderes maléficos.

Los amaníes, en Antioquia, consideraban el contacto con los genitales femeninos como un antídoto con- 
tra las mordeduras de las serpientes venenosas, o contra la acción de los gusanos urticantes. Refiere Fray Pedro de Aguado que "en la hora que se siente el hombre mordido por este gusano, a quien en esta tierra llaman sabandija por su mala propiedad, luego acude a buscarlo y si lo halla mátalo y sácale las tripas, y con el herbaje que dentro de ellas halla se unta la picadura, con que ataja todo dolor y alteración, y si acaso sucedió morderle de noche y en parte donde no puede haber el gusano para remediarse con él, si la picadura fue en el dedo o en parte semejante, métela en el sexo de la mujer, y con aquesto ataja la furia de la ponzoña, de suerte que esta manera de curar me parece que con una ponzoña se cura otra". Es de anotar que al cronista Aguado le llamó mucho la atención el hecho de que en la provincia habitada por los amaníes abundaran los hermafroditas. No sabemos si en verdad fuera así o si acostumbraran, como los laches del noroeste de los Andes Orientales, a criar como mujer cada quinto hijo varón.

Las mujeres pantagoras, vecinas del noroeste de Antioquia, tuvieron fama por la tersura del cutis, producto según Aguado de "beber cierta cáscara de árbol que parece canela, por parecerse a ella, porque con la virtud de esta cáscara detienen su regla mujeril cinco o seis meses, con lo cual no se avejentan mucho ni se les arruga el rostro si no es por demasiado curso del tiempo, y luego al cabo de este tiempo les torna a bajar".

\section{BIBLIOGRAFIA}

1 AGUADO, FRAY PEDRO DE. "Recopilación historial". Biblioteca de Historia Nacional. Imprenta Nacional. Bogotá, 1906.
2 ARANGO C. JESUS. "Mitos, leyendas y dioses chibchas". Biblioteca de autores caldenses. Manizales, 1965.

3 BERGUA, JUAN B. "Mitología Universal". Ediciones Ibérica. Madrid, 1960.

4 CASTELLANOS, JUAN DE. "Elegía de varones ilustres de Indias". Editorial Suramérica. Caracas, 1932.

5 FRIEDE, JUAN. "Invasión del país de los chibchas". Ediciones Tercer Mundo. Bogotá 1966.

6 LEONARDO, RICHARD. "Historia de la Ginecología". Salvat Editores. Barcelona, 1948.

7 MARTINEZ, HEBERTO. "América India". Editorial Aguila. Bogotá, 1938.

8 PEREZ DE BARRADA, JOSE. "Los muiscas antes de la Conquista". Consejo Superior de Investigaciones Científicas (Instituto Bernardino de Sahagún). 1951.

9 RECLUS, ELISEO. "Colombia". Biblioteca Schering Corporation U.S.A. Bogotá, 1965.

10 ROBLEDO, EMILIO. "Apuntaciones sobre la Medicina en Colombia". Biblioteca de la Universidad del Valle. Cali, 1959.

11 RODRIGUEZ FREIRE, JUAN. "EI Carnero". Bibliateca de Cultura Colombiana. Bogotá, 1963.

12 SIMON, FRAY PEDRO. "Noticias historiales de las conquistas de Tierra Firme en las Indias Occidentales". Bogotá, 1953.

13 TRIANA, MIGUEL. "La civilización chibcha". Biblioteca Banco Popular. Bogotá, 1970.

14 TRIMBORN, HERMANN. "Señorío y barbarie del Valle del Cauca". Consejo Superior de Investigaciones Científicas. Madrid, 1949.

15 ZAMORA, FRAY ALONSO DE. "Historia de la Provincia de San Antonia del Nuevo Reyno de Granada". Biblioteca Popular de Cultura Colombiana. Bogotá, 1945.

16 ZUBIRIA, ROBERTO DE. "Orígenes del complejo de Edipo". (De la mitología griega a la mitología chibcha). Ediciones Tercer Mundo. Bogotá, 1968. 